\title{
EFFECTS OF BIOTIN-BINDING PROTEINS ON EIGHT SPECIES OF PASTURE INVERTEBRATES
}

\author{
L.A. MALONE ${ }^{1}$, E.P.J. BURGESS ${ }^{1}$, C.F. MERCER ${ }^{2}$, \\ J.T. CHRISTELLER ${ }^{3}$, M.T. LESTER ${ }^{3}$, C. MURRAY ${ }^{3}$, M.M. PHUNG ${ }^{3}$, \\ B.A. PHILIP ${ }^{1}$, E.L. TREGIDGA ${ }^{1}$ and J.H. TODD ${ }^{1}$
}

${ }^{1}$ HortResearch, Private Bag 92169, Auckland, New Zealand ${ }^{2}$ AgResearch, Private Bag 11008, Palmerston North, New Zealand

${ }^{3}$ HortResearch, Private Bag 11030, Palmerston North, New Zealand

Corresponding author: Imalone@hortresearch.co.nz

\begin{abstract}
Biotin-binding proteins (BBPs), such as avidin and streptavidin, represent potent insect control compounds which could be delivered via transgenic plants. The effects of BBPs on some pasture pests were determined. Black field cricket nymphs (Teleogryllus commodus) had significantly reduced growth and survival when fed on lettuce leaves painted with purified avidin. Adult clover root weevils (Sitona lepidus) were unharmed when fed clover foliage painted with avidin. In contrast, neonate or one-weekold S. lepidus larvae had poor survival when fed on artificial diets containing avidin or streptavidin. Neonate larval Argentine stem weevils (Listronotus bonariensis) had significantly reduced survival when fed with artificial diet containing streptavidin or avidin. Slugs (Deroceras reticulatum) and snails (Cantareus aspersus) were not harmed when fed with avidin-painted lettuce. Similar numbers of eggs were laid and galls produced by the root-knot nematodes, Meloidogyne javanica, Meloidogyne hapla and Meloidogyne incognita, inoculated onto transgenic tobacco plants expressing avidin and non-transgenic controls.

Keywords: biotin-binding proteins, insects, molluscs, nematodes, transgenic plants.
\end{abstract}

\section{INTRODUCTION}

Resistant or tolerant forage plant cultivars represent an attractive option for pasture pest control, since hilly terrain, pest feeding habits, pest species diversity and the perennial nature of the crop can make chemical or cultural control difficult. The ability to genetically modify forage plants extends the range of potential pest-resistance traits which may be incorporated into such cultivars.

Biotin-binding proteins (BBPs) represent a new class of anti-insect compounds for expression in transgenic plants (Kramer et al. 2000; Murray et al. 2002). Avidin, from chicken egg white, and streptavidin, from the bacterium Streptomyces avidinii, are active against insects from many orders and mites (Morgan et al. 1993; Kramer et al. 2000; Markwick et al. 2001). Transgenic plants expressing 2 to $20 \mu \mathrm{M}$ avidin have been found to be effectively protected from insect attack (Burgess et al. 2002). Biotin nutrition in insects is not fully understood, but this vitamin is a co-factor of major carboxylases involved in gluconeogenesis, lipogenesis, fatty acid and amino acid catabolism (Knowles 1989). Insects cannot synthesise biotin and must obtain it from their food or their intestinal microflora. Insect bioassays suggest that even relatively low levels of BBPs can create a lethal biotin deficiency in many insects. Their effects on molluscs and nematodes are unknown.

To assess the potential for using BBP genes in transgenic forage plants for pest control, the effects of feeding purified BBPs or BBP-transgenic plants to a range of pasture invertebrates were determined.

New Zealand Plant Protection 55:411-415 (2002) 


\section{MATERIALS AND METHODS}

Black field cricket (Teleogryllus commodus (Orthoptera))

Organically grown lettuce leaves were painted on both sides with one of three solutions: $0.1 \%$ (v:v) BondXtra ${ }^{\circledR}$ (a wetting, spreading and sticking agent) (controls), $4.8 \mu \mathrm{M}$ avidin in BondXtra ${ }^{\circledR}$ or $19.2 \mu \mathrm{M}$ avidin in BondXtra ${ }^{\circledR}$. Four-day-old black field cricket nymphs from a laboratory colony were weighed and placed individually on leaves in vented specimen pottles lined with filter paper. There were 20 nymphs per treatment. Fresh leaves were provided as required. Crickets were weighed weekly until all avidin-treated individuals had died. Clover root weevil adults (Sitona lepidus (Coleoptera))

Adult clover root weevils (CRW) were field-collected from Ruakura and placed individually in vented containers, each containing a single painted white clover leaf with its stem embedded in $0.4 \%$ agar. Undersides of leaves were painted with a control solution of $0.1 \%$ Bond Xtra ${ }^{\circledR}, 26 \mu \mathrm{M}$ avidin in Bond Xtra ${ }^{\circledR}$ or $51 \mu \mathrm{M}$ avidin in Bond $\mathrm{X}$ tra ${ }^{\circledR}$. There were 15 to 18 weevils per treatment, replicated three times. Survival was recorded every weekday until all insects had died.

Clover root weevil larvae

CRW eggs were obtained from field-collected adults maintained on white clover foliage. Larvae were transferred individually to microtitre plate wells containing Argentine stem weevil (ASW) diet (Malone \& Wigley 1990) without biotin and sealed with transparent film. This diet, with biotin supplied only through the natural ingredients and not added in purified form to a concentration of $1.3 \mu \mathrm{M}$ as in the original recipe, was used for both controls and treatments. This diet may more closely resemble the weevils' plant food, since plants typically contain less than $0.7 \mu \mathrm{M}$ biotin (J. Christeller, unpubl. data). Diet, into which $60 \mu \mathrm{M}$ streptavidin had been blended thoroughly, was fed to 100 neonate larvae, while 100 control larvae were given diet without additive. The experiment was replicated three times, and larvae were examined each weekday until all had died. In a second experiment which was replicated three times, FRW (Fuller's rose weevil) diet (G. Clare, pers. comm.) without biotin was fed to 10 one-week-old larvae (controls) and another group of 10 larvae were given the same diet containing $55 \mu \mathrm{M}$ avidin. This experiment was terminated after 56 days.

Argentine stem weevil larvae (Listronotus bonariensis (Coleoptera))

ASW eggs were obtained from field-collected adults maintained on ryegrass foliage. These were placed directly onto blocks of ASW diet without biotin in individual sealed containers. Thirty one insects received diet with $60 \mu \mathrm{M}$ streptavidin, 20 each received diet with 2,5 , or $20 \mu \mathrm{M}$ avidin and 51 received control diet. The experiment was replicated three times. Survival was recorded approximately weekly, fresh diet was supplied as required and the experiment terminated on Day 34.

Slugs and snails (Mollusca)

Slugs (Deroceras reticulatum) and snails (Cantareus aspersus) were collected from Auckland gardens, weighed and placed in groups into sealed plastic containers. They were fed organically grown lettuce leaves painted with the three solutions described above for crickets. Each treatment had two replicates of ten snails and five replicates of five slugs. Snails were individually identified by numbers on their shells. Containers were checked daily, sprayed with water and lettuce replenished as necessary. At Day 51, all surviving animals were weighed and the experiment terminated.

Root-knot nematodes (Meloidogyne spp. (Nematoda))

Twenty transgenic $\mathrm{T}_{1}$ tobacco plants with leaf expression levels of 2.4 to $26.1 \mu \mathrm{M}$ avidin were grown from seed (Christeller et al. 1999). Earlier measurements from similar plants had demonstrated a linear correlation between leaf and root avidin levels in individual plants. Controls were 20 non-transgenic plants. Two-week-old plants were re-potted and a week later five transgenic and five control plants were inoculated with one of three nematode species, Meloidogyne javanica, M. hapla or M. incognita, by injecting a suspension containing 4000 eggs into holes around the roots. A further five plants of each type were sham-inoculated with water. Seven weeks after inoculation, the roots were washed and galls counted. The galls were then crushed, the eggs sieved from them and counted. 


\section{Statistical tests}

ANOVA was used to compare insect body mass at each weighing occasion and numbers of galls and eggs in the nematode experiment. Log-rank tests were used to compare Kayden-Meir estimates of survival distribution S(t) (Kalbfleisch \& Prentice 1980) from survival data recorded throughout each experiment.

\section{Black field crickets}

\section{RESULTS AND DISCUSSION}

Black field crickets had poor growth and survival on avidin-painted lettuce. By Day 21, control crickets were significantly larger than those surviving avidin treatment $(\mathrm{P}<0.05)$. Crickets fed avidin had significantly poorer survival than control crickets $(\mathrm{P}<0.001)$, with no significant difference between the two avidin treatments (Fig. 1a). These results suggest that this pasture pest, and perhaps other Orthoptera, may be susceptible to transgenic plants expressing avidin.

Clover root weevil adults

The survival of CRW adults was not affected by avidin-painted clover. There were no significant differences in survival between adult CRW fed clover leaves painted with avidin $(26$ or $51 \mu \mathrm{M})$ or the control solution (Fig. 1b). This result supports the idea that BBPs act by interfering with insect moulting (Markwick et al. 2001). It also suggests that transgenic avidin-expressing clover would not harm CRW adults. This lack of effect may not preclude control of this pest by this method, since it is larval damage to plants which is thought to cause economic pasture loss (Willoughby et al. 1998).

Clover root weevil larvae

CRW larvae had reduced survival when fed diets containing streptavidin or avidin. In the first experiment (neonates on ASW diet), CRW larvae fed on streptavidin-diet had poorer survival than the controls $(\mathrm{P}<0.001)$ (Fig. 1c). Control weevils had poorer survival than might be expected in the field and only four of these developed into adults before the end of the experiment. No adults emerged among the streptavidin-fed CRW. In the second experiment (week-old larvae on FRW diet), larvae fed with avidin-diet were significantly shorter-lived than the controls $(\mathrm{P}<0.001)$ (Fig. 1c). Many of the BBP-treated CRW appeared to have died during or immediately after a larval moult. Despite attempts to improve the artificial diet used, this test system was hardly ideal, producing high control mortality and possibly masking the potential for BBPs to control these insects. Most larval CRW in these experiments were hardly growing, they were not moulting and thus perhaps not especially susceptible to the effects of the BBP. Test systems using whole clover plants cultured hydroponically on slantboards have been developed for assessing larval weevil damage (Gerard 2001) and transgenic clover plants expressing BBPs could perhaps be assessed in this way.

Argentine stem weevil larvae

ASW larvae had reduced survival on streptavidin- or avidin-diets. Larval survival was significantly lower for weevils fed streptavidin $(60 \mu \mathrm{M})$ or avidin at 2,5 or $20 \mu \mathrm{M}$ than for the controls $(\mathrm{P}<0.001)$ (Fig. 1d). As with the CRW larvae, ASW larvae given BBPs appeared to have died during moulting.

\section{Snails and slugs}

Snails and slugs were apparently unaffected by avidin-painted lettuce. Snails had similar mean initial weights: $619.9 \pm 50 \mathrm{mg}$ for controls, $581.8 \pm 42.1 \mathrm{mg}$ on $4.8 \mu \mathrm{M}$ avidin and $592 \pm 50.5 \mathrm{mg}$ on $19.2 \mu \mathrm{M}$ avidin. All snails grew during the 51-day experiment and there were no significant differences in final weights between the three groups: $736.8 \pm 45.2 \mathrm{mg}$ for controls, $714.3 \pm 48.5 \mathrm{mg}$ on $4.8 \mu \mathrm{M}$ avidin and $730.6 \pm 38.9 \mathrm{mg}$ on $19.2 \mu \mathrm{M}$ avidin. Few snails died during the experiment (Fig. 1e). There were no significant differences in mean snail longevity between the three groups.

Slugs also had similar mean initial weights: $99.9 \pm 2.5 \mathrm{mg}$ for controls, $104.1 \pm 1.1 \mathrm{mg}$ on $4.8 \mu \mathrm{M}$ avidin and $98.6 \pm 2.9 \mathrm{mg}$ on $19.2 \mu \mathrm{M}$ avidin. Each group of slugs consumed the lettuce supplied, but all lost weight during the experiment. Final mean weights were: $28.4 \pm 4.3 \mathrm{mg}$ for controls, $44.2 \pm 6.1 \mathrm{mg}$ on $4.8 \mu \mathrm{M}$ avidin and $34.0 \pm 5.3 \mathrm{mg}$ on $19.2 \mu \mathrm{M}$ avidin. There were no significant differences attributable to the treatments in 

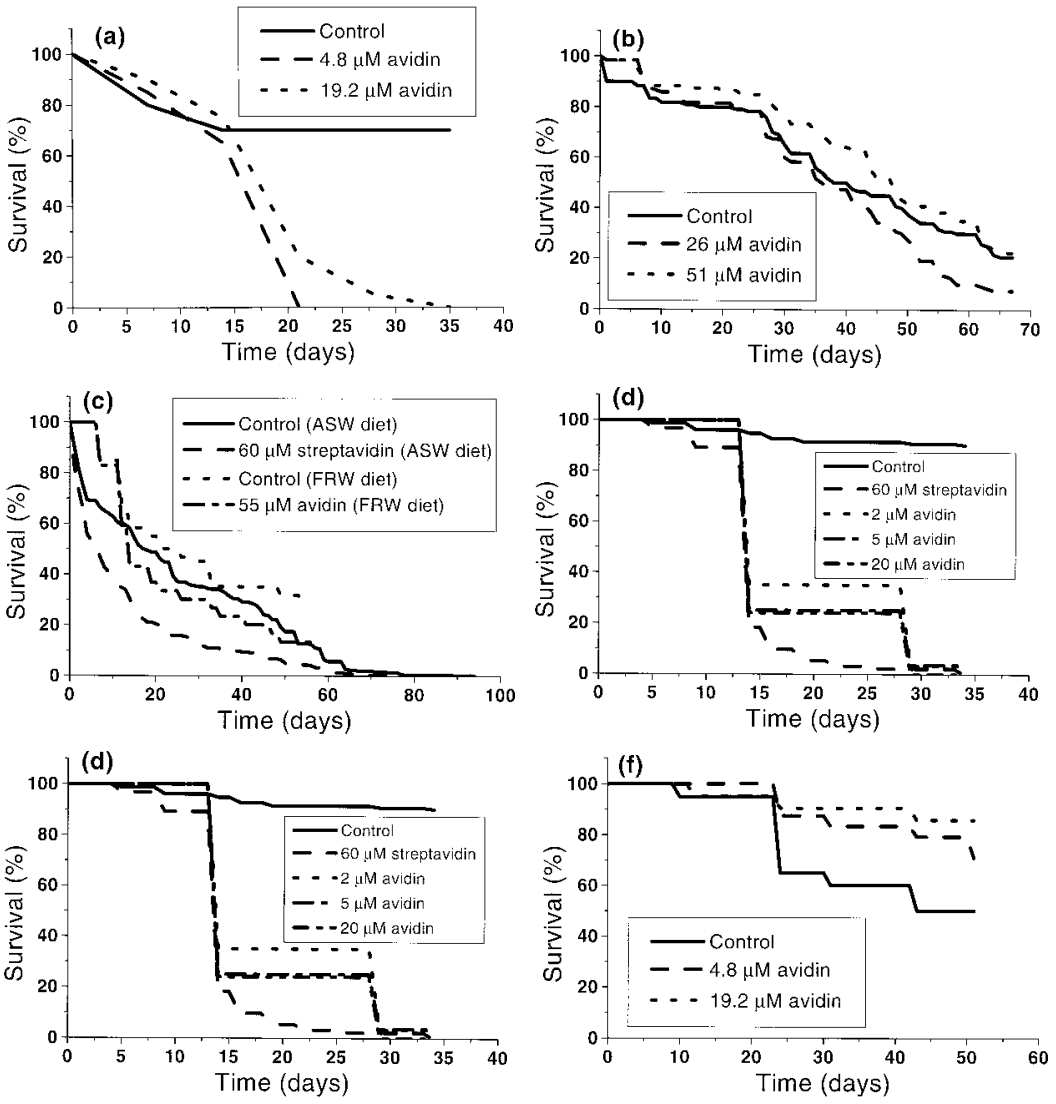

FIGURE 1: Mean survival of (a) black field cricket nymphs fed with avidin-painted lettuce, (b) clover root weevil adults fed with avidin-painted clover, (c) clover root weevil larvae fed with streptavidin- or avidin-diets, (d) Argentine stem weevil larvae fed with streptavidin- or avidin-diets, (e) snails fed with avidin-painted lettuce and (f) slugs fed with avidinpainted lettuce.

initial or final mean slug weights. Slug survival, particularly among the controls, was also poor (Fig. 1f). In fact, slugs on avidin-painted lettuce had significantly greater mean longevity than the control slugs $(\mathrm{P}<0.05)$.

Root-knot nematodes

The three species of root-knot nematodes tested were apparently unaffected by avidin expressed in transgenic tobacco. Mean numbers of galls and eggs of each nematode species were not altered by avidin expression in their host plants and no galls were observed on sham-inoculated plants $(M$. javanica: $121 \pm 18$ galls and $20 \pm 7$ eggs on transgenics, $171 \pm 22$ galls and $24 \pm 14$ eggs on controls; M. hapla: $206 \pm 21$ galls and $60 \pm 16$ eggs on transgenics, $242 \pm 9$ galls and $22 \pm 17$ eggs on controls; $M$. incognita: $24 \pm 3$ galls and $12 \pm 5$ eggs on transgenics, $26 \pm 7$ galls and $19 \pm 8$ eggs on controls). 


\section{CONCLUSIONS}

This paper is the first record of BBP toxicity to an orthopteran species and it adds CRW and ASW larvae to the list of known coleopteran species susceptible to BBPs. BBP toxicity appears not to extend to molluscs and nematodes. It is possible that symbiotic micro-organisms in the guts of slugs and snails (Charrier et al. 1998) can synthesise biotin for their hosts. Nematodes lack symbionts, so perhaps maternally-derived biotin explains their lack of susceptibility. Results with juvenile crickets, CRW and ASW support the idea that BBPs interfere with insect moulting, perhaps via disruption of fat metabolism (Markwick et al. 2001). The results suggest that BBP genes would be good candidates for incorporation into transgenic forage plants for protection against damage by black field cricket and larvae of CRW and ASW.

\section{ACKNOWLEDGEMENTS}

We thank Dr Anne Gunson of HortResearch for statistical analyses. Funding was provided by the NZ Foundation for Research, Science and Technology and HortResearch.

\section{REFERENCES}

Burgess, E.P.J.; Malone, L.A.; Christeller, J.T.; Lester, M.T.; Murray, C.; Philip, B.A.; Phung, M.M.; Tregidga, E.L. 2002: Avidin expressed in transgenic tobacco leaves confers resistance to two noctuid pests, Helicoverpa armigera and Spodoptera litura. Transg. Res. (in press).

Charrier, M.; Combet-Blanc, Y.; Ollivier, B. 1998: Bacterial flora in the gut of Helix aspersa (Gastropoda Pulmonata): evidence for a permanent population with a dominant homolactic intestinal bacterium, Enterococcus casseliflavus. Can. J. Microbiol. 44: 20-27.

Gerard, P.J. 2001: Dependence of Sitona lepidus (Coleoptera: Curculionidae) larvae on abundance of white clover Rhizobium nodules. Bull. Entomol. Res. 91: 149-152.

Kalbfleisch, J.D.; Prentice, R.L. 1980: Statistical Analysis of Failure-Time Data. John Wiley, New York. 321 p.

Knowles, J.R. 1989: The mechanism of biotin-dependent enzymes. Ann. Rev. Biochem. 58: 195-211.

Kramer, K.J.; Morgan, T.D.; Throne, J.E.; Dowell, F.E.; Bailey, M.; Howard, J.A. 2000: Transgenic avidin maize is resistant to storage insect pests. Nature Biotechnol. 18: 670-674.

Malone, L.A.; Wigley, P.J. 1990: A practical method for rearing Argentine stem weevil, Listronotus bonariensis (Coleoptera: Curculionidae) in the laboratory. N.Z. Entomol. 13: 87-88.

Markwick, N.P.; Christeller, J.T.; Lilley, C.M.; Docherty, L.C. 2001: Insecticidal activity of avidin and streptavidin against four species of pest Lepidoptera. Entomol. Exp. Appl. 98: 59-66.

Morgan, T.D.; Oppert, B.; Czapla, T.H.; Kramer, K.J. 1993: Avidin and streptavidin as insecticidal and growth inhibiting dietary proteins. Entomol. Exp. Appl. 69: 97-108.

Murray, C.; Sutherland, P.W.; Phung, M.M.; Lester, M.T.; Marshall, R.K.; Christeller, J.T. 2002: Expression of biotin-binding proteins, avidin and streptavidin, in plant tissues using plant vacuolar targeting sequences. Transgenic Res. (in press).

Willoughby, B.; Addison, P.; Baker, M. 1998: Clover root weevil (Sitona lepidus) - a threat to the sustainability of white clover in New Zealand pastures? Proc. N.Z. Grassland Assoc. 59: 23-27. 